\title{
Ultrasound findings in patients with Visceral Leishmaniasis
}

\author{
Elsafi Ahmed Abdalla ${ }^{1}$, Caroline Edward Ayad, ", Adam Mohammed Fadl Ahmed ${ }^{2}$, \\ Amel Saeed Abdelrahim ElGaddal ${ }^{1}$, Abdelmomeim Saeed ${ }^{3}$ \\ ${ }^{1}$ Radiology Department, College Of Medical Radiological Science, Sudan University Of Science And Technology, Khartoum, Sudan \\ ${ }^{2}$ Ultrasound Department, Omdurman Tropical Disease Teaching Hospital, Omdurman, Sudan \\ ${ }^{3}$ National College of Medical and Technical studies, Khartoum, Sudan
}

\section{Email address:}

dr.elsafi@gmail.com (E. A. Abdalla), carolineayad@yahoo.com (C. E. Ayad), adammohammed@yahoo.com(A. M. Fadl), Amelgadal@yahoo.com(A. S. A. ElGaddal), abdlmonemsaeed@yahoo.com(A. Saeed)

\section{To cite this article:}

Elsafi Ahmed Abdalla, Caroline Edward Ayad, Adam Mohammed Fadl Ahmed, Amel Saeed Abdelrahim ElGaddal, Abdelmomeim Saeed. Ultrasound Findings in Patients with Visceral Leishmaniasis. International Journal of Medical Imaging. Vol. 2, No. 1, 2014 , pp. 5-9. doi: 10.11648/j.ijmi.20140201.12

\begin{abstract}
Visceral leishmaniasis(VL) has been a major health burden on the Sudanese patients and to the health authorities in Sudan. Delay in diagnosis of VL leads to serious complications and eventually death. This study aimed to study the ultrasonographic findings of VL in Sudanese patients.50 Sudanese patients who were clinically diagnosed as VL, attended to Ultrasound Department and were scanned for abdomen. Subject's ages, duration of the disease, liver, spleen, lymph nodes, portal vein and inferior vena cava (IVC) diameter, presence of asites and plural effusion, echogenicity of kidneys and pancreas were evaluated. VL affected the age group $15-30$ years in 20 patients $(40 \%)$ constituting the high incidence and it was less common in age group $<15$ years $(10 \%)$. The diseases was common in males $(76 \%)$ than females $(24 \%)$ with a ratio of (3.6: 1). The Eastern states constituted the high incidence of the diseases among the other states $27(54.0 \%)$, and Khartoum State constituted the lower incidence 1(2\%). Splenomegally, hepatomegally, lymphadenopathy were the most common ultrasound findings. Portal vein, IVC dilatations were less common and were significantly affected with duration of diseases at $p$ value $\square 0.0001$. VL associated with asites and plural effusion was found in the sample and has statistically significant relation at $p$ value $\square 0.02$. Ultrasound detected changes in kidneys and pancreases echogenecity with prolonged disease duration. Ultrasonography has the capability of diagnosis of VL and by using ultrasound complications could be diagnosed earlier and treated before damaging the spleen, liver, lymph nodes or death to occur.
\end{abstract}

Keywords: Visceral Leishmaniasis, Ultrasound, Tropical Diseases

\section{Introduction}

Visceral leishmaniasis (VL) known as kala-azar, black fever, and Dumdum fever [1]Leishmaniasis is caused by parasites of the Leishmania genus. This disease is the second-largest parasitic killer in the world, responsible for an estimated 500,000 infections each year worldwide [2].The parasite migrates to the internal organs such as liver, spleen and bone marrow, and results in the death of the host. Signs include substantial swelling of the liver and spleen. [3]

While the disease's geographical range is broad, it is not continuous. The disease clusters around areas of drought, famine, and high population density. In Africa, this has caused a great problem in Sudan, Kenya, and Somalia.

In the Sudan, kala-azar was concentrated in the Southern border or into the Western part of the country [4]

VL (Kala-azar) is a protozoal infection common in underdeveloped countries; Leishmania infantum is the main cause of VL in the Mediterranean region [5, 6, 7.]Infected animals, mainly dogs are the carriers of the disease in the Mediterranean [8]. An insect bite is the vector of transmission. People from unaffected areas, may contract the disease $[9,10]$ after visiting endemic areas. Cases of leishmaniasis in overseas travelers and US Gulf War veterans have prompted growing interest in this disease [6, 11]. Factors increasing the risk of clinical development of the disease include malnutrition, immune suppression, and most importantly HIV infection [5] Delay and difficulties in diagnosis are common, especially in the early stages of the disease, due to non-specific symptomatology and difficulties 
in demonstrating intracellular protozoa in tissue aspirates [12] Intracellular leishmania can be identified from aspirates of spleen, bone marrow, lymph node, or liver [5]The CT findings of hepatosplenomegaly, and abdominal lymphadenopathy secondary to visceral leishmaniasis were previously reported [12,13]. Patients with advanced Kala-azar die without treatment.

Visceral leishmaniasis (VL) needs quick, accurate, safe non invasive method for diagnosis; so this study was obtained for subjects coming to tropical hospitals in the Sudan using ultrasonography

\section{Objectives}

The objectives of this study were to evaluate the diagnostic role of ultrasound as well as to study the sonographic findings in Sudanese subjects affected with VL

\section{Materials and Methods}

This study was conducted at Omdurman Tropical Diseases Teaching Hospital in Sudan during the period from March up to August 2011

Ultrasound machine, version Aloka (500) (manufacture 2007).Probes (transducers) curve linear $(3.5,5,7.5,10 \mathrm{MHz})$ and convex $(3.5,5,7.5 \mathrm{MHz})$ was used

50 Sudanese patients who were positively diagnosed as visceral leishmaniasia were included and non Sudanese patients and normal subjects were excluded.

Data including (a) personal information (age, gender, locality and duration of illness) (b) Ultrasonic findings of abdominal examination (size of spleen, liver, lymph nodes, caliber of portal vein and vena cava, level of plural and ascitic fluid, echogenicity of pancreas and kidneys) were all been evaluated. Data were collected on data sheet and were statistically analyzedusing SPSS programme version 16 .

The ultrasound examinations were done after explaining the procedure to the patients. The patients came fasting for 8 hours, positioned in the couch comfortably in supine position. Couple gel was applied to the abdomen; the patients were allowed to breathe quietly and deeply. The transducer was chosen and the gain was corrected. The scanning was taken in all directions (longitudinal and transverse views).

As for spleen, the long axis was measured (normal size $<13 \mathrm{~cm}$, mild splenomegally $13-15 \mathrm{~cm}$, moderate splenomegally $15.1-19.9 \mathrm{~cm}$, marked splenomegally $>20$ $\mathrm{cm}$ ). Liver was measured in mid clavicular line (normal size $<13 \mathrm{~cm}$, mild hepatomegaly $13.1-15 \mathrm{~cm}$, moderate hepatomegaly $15.1-18 \mathrm{~cm}$, and marked hepatomegaly $>18$ $\mathrm{cm}$ ). lymph nodes were measured in the long axis (normal size $<2 \mathrm{~cm}$, mild lymphadenopathy $2.1-2.5 \mathrm{~cm}$, moderate lymphadenopathy $2.6-3 \mathrm{~cm}$ and marked lymphadenopathy $>3 \mathrm{~cm}$ ). Regarding IVC diameter (normal $<2.4 \mathrm{~cm}$, dilated if $>2.5 \mathrm{~cm}$ ) and portal vein diameter (normal $13 \mathrm{~mm}$, dilated $>13 \mathrm{~mm}$ ). Concerning pancreas size it was measured in long axis (normal $15-20 \mathrm{~cm}$, increased $>20 \mathrm{~cm}$ ) and kidneys size were measured in long axis (normal $8-12 \mathrm{~cm}$, increased $>12 \mathrm{~cm}$ ). Plural fluid/ effusion were present if the distance between the lung and chest wall $\geq 50 \mathrm{~mm}(500 \mathrm{ml})$ and ascites was present if $>100$ $\mathrm{ml}$ free fluid was presented in the peritoneal cavity.

\section{Results}

Fifty Sudanese patients with visceral leishmaniasis were studied by ultrasound at Omdurman Tropical Diseases Teaching Hospital during the period from March to August 2011. VL were more common in males $(76 \%)$ than females (24\%) the ratio was $(3.6: 1)$

Ultrasound findings were more common in age group 15 - 30 years $(40 \%)$, and $31-45$ years $(36 \%)$, while less common in the age group $>45$ years $(14 \%)$ and $<15$ years $(10 \%)$

According to geographic areas, VL was found common in the population studied from Eastern states (54\%) and central states $(26 \%)$, a considerable percentage $(10 \%)$ in Southern states, and less common in Western and Northern states (4\%) each, while very rare in Khartoum State (2\%) .

The tables below presented the study results.

\section{Discussion}

In Sudan, Leishmania was studied long time ago [14]. The current study showed that Eastern States were more affected than other states. Similar studies showed that the visceral leshmania has hyper endemic foci and was mainly in East and South of the country $[15,16]$

The disease showed wild diversity in clinical pattern but the pathogenicity depends mainly on parasite genotype versus host immunogenic profile. [17]

Regarding US findings in the study population, $(6 \%)$ of patients have normal ultrasound; majority (94\%) had splenomegaly, (90\%) lymph adenopathy, and (86\%) hepatomegaly. Less commonly had ascites (26\%) and pleural effusion (18\%). Rare US findings were portal vein dilatation (10\%), inferior vena cava dilatation (8\%) and very rarely increased echogenicity of the kidneys (4\%) and decreased echogenecity of the pancreas $(2 \%)$ as shown in (Table 1). These results were justified by delayed attendance of the patients to the hospital, constituting to what was written in the literature [18, 19]

The study showed that the duration of disease can affect the presence of hepatomegally, splenomegally and lymphoadenopathy significantly at $P \square 0.0001$ as presented in table (2) in addition to the presence of ascites and plural effusion with significant relation at $p \square 0.000$ and 0.002 respectively Table (3) Ascites was found to be less common in our study, constituting with the literature (19)

The portal vein and Inferior vena cava were detected to be dilated significantly at $P$ values $\square 0.016$ and $\square 0.029$ respectively as the duration of the illness increased as presented in table (4) . This may be due to the portal hyper tension that acts as a complication of visceral leishmaniasis. 
Portal vein and inferior vena cava dilatation were rare in our study, this is similar to Parasad's study about portal hypertension in VL, which showed presence of portal hypertension and dilatation of hepatic veins in 10 out of 88 cases studied in India [20], also similar to Salmi study [21], and similar to what was observed in Moslihi's study that showed the presence of pancreatitis (decreased echogeneicity) and renal tissue involvement (increased echogeneicity) in few patients studied by ultrasound in southern Iran [22], and similar to Saunders study [23 ].

Based on the results of this study, the researchers concluded that patients living in Eastern Sudan were highly exposed to the risk of infection by VL. Large variation in the geographical distribution of infection cases highlights the presence of environmental and/or social factors, which identity the relevance risk of VL. Clinical concerns should arise in patients with VL, as significant relation of their clinical conditions was observed with the long existence of the diseases.
Results showed that abdomen ultrasound can detect the changes in organs size in an appropriate manner as well as to demonstrate the echo texture changes as hyper or hypo echogenicity in case of inflammation as pancreatitis and renal inflammatory diseases resulted from VL.

Ultrasound has the ability to find out more than one sign and complication, at the same time has the capability in diagnosis of VL and differentiating it from mimicking conditions, in complement with other laboratory tests.

Delayed diagnosis due to A typical manifestation can lead to fatal outcome in patients. Instead of relying solely on the classical clinical features of visceral leishmaniasis, simple abdominal ultrasound examination can help to make an early diagnosis even in atypical cases, thereby reducing the mortality of visceral leishmaniasis. The usage of ultrasound as a primary model in the diagnosis of patients with VL, and characterization of the signs and complications in Tropical Sudanese hospitals is enlightening

Table 1: Frequency, percentages and distribution according to ultrasound findings.

\begin{tabular}{lll}
\hline Findings & Frequency & Percentage \\
\hline Normal & 3 & $6 \%$ \\
Splenomegally & 47 & $94 \%$ \\
Hepatomegaly & 43 & $86 \%$ \\
Lymphadnopathy & 45 & $90 \%$ \\
Ascites & 12 & $24 \%$ \\
Pleural effusion & 8 & $16 \%$ \\
Portal vein dilatation & 9 & $18 \%$ \\
Inferior vena cava dilatation & 7 & $14 \%$ \\
Increased kidneys echogenicity & 2 & $4 \%$ \\
Decreased panacreas echogenicity & 1 & $2 \%$ \\
\hline
\end{tabular}

Table2 Cross tabulation of visceral leishmaniasis duration/weeks and ultrasound findings( Spleno megally, Hepatomegally,Lymphadenopathy)

\begin{tabular}{|c|c|c|c|c|c|c|}
\hline \multicolumn{7}{|c|}{ Crosstab tabulation } \\
\hline & \multirow[b]{2}{*}{ Weeks } & \multicolumn{4}{|c|}{ Spleno megally* } & \multirow{2}{*}{ Tota } \\
\hline & & normal & mild & moderate & huge & \\
\hline \multirow{3}{*}{$\begin{array}{l}\text { *Illness } \\
\text { Duration }\end{array}$} & Less than 4 & 3 & 1 & 0 & 0 & 4 \\
\hline & $4-8$ & 0 & 4 & 10 & 7 & 21 \\
\hline & More than 8 & 0 & 0 & 0 & 25 & 25 \\
\hline \multirow[t]{2}{*}{ Total } & & 3 & 5 & 10 & 32 & 50 \\
\hline & & \multicolumn{4}{|c|}{ Hepato megally* } & \\
\hline \multirow{3}{*}{$\begin{array}{l}\text { *Illness } \\
\text { Duration }\end{array}$} & & normal & mild & moderate & huge & \\
\hline & Less than 4 & 4 & 0 & 0 & 0 & 4 \\
\hline & $4-8$ & 3 & 9 & 9 & 0 & 21 \\
\hline \multirow{4}{*}{ Total } & More than 8 & 0 & 0 & 0 & 25 & 25 \\
\hline & & 7 & 9 & 9 & 25 & 50 \\
\hline & & \multicolumn{4}{|c|}{ Lymph adenopathy* } & \\
\hline & & normal & mild & moderate & huge & \\
\hline *Illness & Less than 4 & 4 & 0 & 0 & 0 & 4 \\
\hline \multirow[t]{2}{*}{ Duration } & $4-8$ & 1 & 5 & 10 & 5 & 21 \\
\hline & More than 8 & 0 & 0 & 0 & 25 & 25 \\
\hline Total & & 5 & 5 & 10 & 30 & 50 \\
\hline
\end{tabular}


Table3 Cross tabulation of visceral leishmaniasis duration/weeks and ultrasound findings (presence of Ascites and Plural effusion)

\begin{tabular}{|c|c|c|c|c|}
\hline \multicolumn{4}{|c|}{$\begin{array}{l}\text { Cross tabulation } \\
\text { *Ascites }\end{array}$} & Total \\
\hline \multirow{3}{*}{$\begin{array}{l}\text { *Illness } \\
\text { Duration }\end{array}$} & Less than 4 & 4 & 0 & 4 \\
\hline & $4-8$ & 21 & 0 & 21 \\
\hline & More than 8 & 13 & 12 & 25 \\
\hline Total & & 38 & 12 & 50 \\
\hline \multicolumn{5}{|c|}{$* *$ Plural effusion } \\
\hline \multirow{3}{*}{$\begin{array}{l}\text { *Illness } \\
\text { Duration }\end{array}$} & Less than 4 & 4 & 0 & 4 \\
\hline & $4-8$ & 21 & 0 & 21 \\
\hline & More than 8 & 17 & 8 & 25 \\
\hline \multicolumn{2}{|l|}{ Total } & 42 & 8 & 50 \\
\hline \multicolumn{2}{|c|}{${ }^{* *}$ Correlation is significant at $p \square 0.002$} & significa & & \\
\hline
\end{tabular}

Table4 Cross tabulation of visceral leishmaniasis duration/weeks and ultrasound findings (Portal Vein and IVC Diameter dilatation).

\begin{tabular}{|c|c|c|c|c|}
\hline \multicolumn{5}{|c|}{ Cross tabulation } \\
\hline & \multirow[b]{2}{*}{ Weeks } & \multicolumn{2}{|c|}{ *Portal Vein Diameter } & \multirow{2}{*}{ Total } \\
\hline & & Normal & Dilated & \\
\hline \multirow{3}{*}{$\begin{array}{l}\text { *Illness } \\
\text { Duration }\end{array}$} & Less than 4 & 4 & 0 & 4 \\
\hline & $4-8$ & 21 & 0 & 21 \\
\hline & More than 8 & 20 & 5 & 25 \\
\hline \multicolumn{2}{|c|}{ Total } & 45 & 5 & 50 \\
\hline \multicolumn{5}{|c|}{ **IVC Diameter } \\
\hline \multirow{5}{*}{$\begin{array}{l}* * \text { Illness } \\
\text { Duration }\end{array}$} & & Normal & Dilated & \\
\hline & Less than 4 & 4 & 0 & 4 \\
\hline & $4-8$ & 21 & 0 & 21 \\
\hline & More than 8 & 21 & 4 & 25 \\
\hline & & 46 & 4 & 50 \\
\hline
\end{tabular}

Table5 Cross tabulation of visceral leishmaniasis duration/weeks and ultrasound findings (Changes of Echo texture of Kidney and Pancreas) .

\begin{tabular}{|c|c|c|c|c|c|}
\hline \multicolumn{6}{|l|}{ Cross tabulation } \\
\hline & \multirow[b]{2}{*}{ Echogenicity } & \multicolumn{2}{|c|}{ Illness Duration /Weeks } & \multirow[b]{2}{*}{ More than 8} & \multirow{2}{*}{ Total } \\
\hline & & Less than 4 & $4-8$ & & \\
\hline \multirow{2}{*}{$\begin{array}{l}\text { Pancreas } \\
\text { Echogenicity }\end{array}$} & Normal & 4 & 21 & 24 & 49 \\
\hline & Hypo echoic & 0 & 0 & 1 & 1 \\
\hline Total & & 4 & 21 & 25 & 50 \\
\hline \multirow{2}{*}{ Kidney Echogenicity } & Normal & 4 & 21 & 23 & 48 \\
\hline & Hyper echoic & 0 & 0 & 2 & 2 \\
\hline Total & & 4 & 21 & 25 & 50 \\
\hline
\end{tabular}

\section{Acknowledgements}

Many thanks to Omdurman Tropical Disease Teaching Hospital and College of Medical Radiological Science, Sudan University of Science and Technology, Radiology Department to allow the authors to perform this work.

\section{References}

[1] D. James William.; G..Berger Timothy; et al. Andrews' Diseases of the Skin: clinical Dermatology. Saunders Elsevier. 2006 ISBN 0-7216-2921-0 
[2] P. Desjeux "The increase of risk factors for leishmaniasis worldwide". Transactions of the Royal Society of Tropical Medicine and Hygiene 2001,95 (3): 239-43.

[3] "Leishmaniasis and HIV co-infection". WHO.

[4] Jean, Francois "Sudan: Speak no Evil, Do no Good". Life, Death and Aid: the Médecins Sans Frontières Report on World Crisis Intervention. (1995).

[5] PJ. Guerin, P. Olliaro, S .Sundar, et al,. Visceral leishamniasis: current status of control, diagnosis, and treatment, and a proposed research and development agenda. Lancet lnfect Dis; 2002, 2:494-501.

[6] BL .Herwaldt. Leishmaniasis. Lancet; 1999, 354:1191-9.

[7] JD .Berman. Human leishmaniasis: clinical, diagnostic, and chemotherapeutic developments in the last 10 years. Clin Infes Dis; 1997,16:251-5.

[8] HW.Murray, Kala-azar - progress against a neglected disease. N Engl J Med; 2002,347:1793-4

[9] C. Granert, G .Elinder, A .Ost, JI.Henter.Kala-azar in a one year-old Swedish child. Diagnostic difficulties because of active hemophagocytosis. Acta Paediatr; 1993,82:794-6.

[10] Y .Büyu"kas,ik, NS. Ileri , , IC. Haznedarog ${ }^{\natural} l u, ~ H$ Demirog lu, S .Dündar.,Fever hepatosplenomegaly, pancytopenia in a patient living in the Mediterreanean region. Postgrad Med J; 1998 ,74:237-41

[11] MW. Pantsan, TA.Coleman.Images in clinical medicine.Kala-azar. N Engl J Med; 2003,349:e13

[12] D Cohen, S.Fields, CT findings in visceral leishmaniasis mimichking lymphoma. Comput Med Imaging Graph; $1988,12: 325-7$

[13] SJ .Deutch, MA. Sandles, MB .Alpern..Abdominal lymphadenopathy in benign disease: CT detection. Radiology; 1987,163:335-8

[14] S.H.M. Neave, , Leishmania donovani in Sudan Bri.Med J., 1904, 1:1252-1252

[15] R Kirk,. M.H.Sati,.Studies in Leshmaniasis in Anglo-Egyptain Sudan 11 The skin and lymph glands in Kala-azar.Trans.R.Soc.Trop Med Hygine, 1940,33:501-506

[16] A.M.El-Hassan, and EE.Zijlstra, , Leshmaniasis in Sudan Transact R.Soc Trop.Med Hygiene, 2001,95:27-58

[17] N.M.Abdalla,.Evaluation of Gene Targeted PCR and Molecular Hybridization used in Diagnosis of Human Leishmania Isolates Biotechnology ISSN 1682-296X ,2010

[18] M Siddig, et al. Visceral leishmaniasis in the Sudan: Comparative parasitological methods of diagnosis. Trans R Soc Trop Med Hyg; 1988,82: 66 -8

[19] WHO. Manual on visceral leishmaniasis control. $\mathrm{WHO} /$ Leis/96.40

[20] www.resources.metapress,( 2009)

[21] www.translate Google, (2009)

[22] www.patient.com. (2009)

[23] www.ijmm. org/Articles, (2010) 